\title{
A presença feminina na exposição Visões da arte no acervo do MAC USP 1950-2000
}

Bruna Fernanda Vieira Silva

\section{Resumo}

Este artigo analisa a presença de artistas mulheres na exposição Visões da arte no acervo do MAC USP 1950-2000, a segunda parte da mostra de longa duração do acervo do Museu de Arte Contemporânea da Universidade de São Paulo (MAC USP), a partir das teorias feministas de arte, pensando tanto na representatividade de artistas mulheres na exposição quanto na questão do gênero dentro do MAC USP como um todo.

Palavras-chave: Artes - Gênero - Feminino - MAC USP - Artes visuais Representatividade. 


\section{Introdução}

A presença de artistas mulheres em museus e galerias é extremamente deficitária por todo o mundo, como diversos levantamentos e trabalhos insistem em denunciar ${ }^{\mathrm{I}}$. Mesmo ocupando grandes porcentagens nas escolas e faculdades de arte, as mulheres artistas ainda estão em minoria nos acervos dos museus, e o número cai ainda mais quando se trata de obras em exposição. Essa ausência produziu importantes questionamentos e mudanças nos eventos de arte, suscitando um debate que reverberou em exposições e salões que tratam especificamente desse tema. Porém, essa realidade permanece ainda hoje, com avanços e retrocessos que variam muito de acordo com o lugar do mundo em que essas mulheres vivem e as instituições às quais estão vinculadas.

Esse tipo de questionamento acerca da presença feminina nas instituições de arte foi muito fomentado pelos trabalhos do grupo estadunidense Guerrilla Girls², que desde I985 produz campanhas e ações em que denuncia essa presença deficitária de artistas mulheres dentro dos museus, em oposição ao grande número de nus femininos. O grupo denunciou ainda outras discrepâncias de gênero e raça por meio de ações em museus norte-americanos e posteriormente em instituições do mundo todo. Desta forma, a crítica às instituições que detêm o poder no mundo da arte se consolidou pelo viés feminista, que, enquanto teoria, já pensava na arte e na história da arte como objeto desde os anos I970, juntamente com o movimento feminista em países anglo-americanos nesse mesmo período (TVARDOVSKAS, 20I5).

É a partir desse cenário que analiso a exposição Visões da arte no acervo do MAC USP 1900-2000, mostra que pretende apresentar as obras mais significativas do acervo do Museu de Arte Contemporânea (MAC) da Universidade de São Paulo (USP). Nela o visitante pode percorrer os últimos cem anos da história da arte de acordo com a curadoria das docentes Ana Magalhães, Helouise Costa e Garmen Aranha (todas curadoras do MAG USP), a partir de conjuntos definidos pelas principais escolas e movimentos artísticos desse período, dando destaque às suas crises e rupturas (BRANDÃO, 20I6). A mostra, que começou em setembro de 20I6, está dividida em dois andares e tem a previsão de permanecer aberta à visitação por cinco anos. $\mathrm{O} 7^{\circ}$ andar do museu cedia as obras que correspondem à primeira metade do século XX e o $6^{\circ}$ andar abriga as obras da segunda metade do século XX. Essa divisão não é estrita-

I Sobre o tema, cf. Barbosa (2003), Pollock (I988) e Fonseca (2013).

2 Sobre Guerrilla Girls: <http://www.guerrillagirls.com/>. 
mente cronológica, ela corresponde principalmente a uma divisão entre as categorias de arte moderna e arte contemporânea ${ }^{3}$. Por esse motivo, focarei a análise na segunda parte da exposição, denominada Visões da arte no acervo do MAC USP 1950-2000, a fim de melhor delinear as particularidades da arte contemporânea nesse contexto. Ainda assim, não deixarei de pensar no projeto da exposição como um todo, assim como seu papel dentro da história e funcionalidade do MAC USP.

\section{A presença feminina na exposição Visões da arte no acervo do MAC USP 1950-2000}

A exposição Visões da arte no acervo do MAC USP 1900-2000 foi pensada depois de uma série de mostras que trabalharam com as principais obras do acervo do MAC USP, sendo a primeira planejada para permanecer acessível em longo prazo.

O Museu de Arte Contemporânea foi criado em I963 quando a Universidade de São Paulo recebeu o acervo do antigo [Museu de Arte Moderna] MAM de São Paulo, formado pelas coleções do casal de mecenas Yolanda Penteado e Ciccillo Matarazzo, pelas coleções de obras adquiridas ou recebidas em doação durante a vigência do antigo MAM e pelos prêmios das Bienais de São Paulo, até I96 I ${ }^{4}$.

Desta forma, o museu possui um importante acervo com obras de arte caracterizadas modernas, como, por exemplo, de Amadeo Mondigliani, Pablo Picasso, Joan Miró, Wassily Kandinsky, Tarsila do Amaral, Anita Malfatti, Emiliano Di Cavalcanti, entre outros. Em decorrência da grande importância desse acervo, o MAC USP procura expor constantemente essas obras, como a primeira parte da exposição, Visões da arte no acervo do MAC USP 19001950 , mostra.

Essa exposição, localizada no $7^{\circ}$ andar do museu, traz obras de Tarsila do Amaral, Anita Malfatti, Lygia Clark e Lygia Pape e mais 16 obras de artistas mulheres de um total de IO3 peças expostas, sendo três obras de Tarsila do

3 Fato explicado pelas curadoras Ana Magalhães e Carmen Aranha durante encontro de formação dos bolsistas da Divisão Técnico-Científica de Educação e Arte do MAG USP Ibirapuera em agosto de 2016.

4 Disponível em: 〈https://bit.ly/IzJuppO>. Acesso em: I4 dez. 2016. 
Amaral, incluindo uma série de nove gravuras da artista. De acordo com Júlia Ayerbe (20I6), é possível ver um desnível no número de homens e mulheres entre os grandes nomes da história da arte no Brasil, comprovado pela importância de artistas modernas e contemporâneas como Anita Malfatti, Tarsila do Amaral, Maria Martins, Lygia Clark, Lygia Pape, Mira Schendel, Beatriz Milhazes e Adriana Varejão. A autora reitera, no entanto, que essa particularidade da arte brasileira não implica a existência de uma igualdade de gêneros neste campo, e salienta a necessidade da questão ser mais bem aprofundada entre as pensadoras nacionais a fim de compreender o motivo desta não ter sido formulada anteriormente. Por esse motivo, não aprofundarei a análise nessa primeira parte da exposição ${ }^{5}$.

Chamo atenção aqui, entretanto, para a escolha curatorial que se atém aos nomes consagrados pela historiografia da arte brasileira. Porém, a presença feminina corresponde ainda a menos de $20 \%$ do total de obras expostas. Ademais, apesar da importância das artistas mulheres no modernismo brasileiro, é possível afirmar que nenhuma delas tem um compromisso ou uma produção considerada, por elas ou por outros, como feminista, ou mesmo em que o gênero pese como característica estruturante da produção, o que pode lançar luz sobre a motivação para essa importância atribuída a tais obras.

Mais recente que a referida exposição de longa duração, o MAG USP inaugurou a sala $A$ instauração do moderno, pensada como um recorte complementar à referida Visões da arte, em que é apresentado o processo de estabelecimento da arte moderna no Brasil por meio de obras importantes deixadas de fora da seleção curatorial. Das 23 obras expostas, apenas três são de artistas mulheres, correspondendo a I3\% do total de obras na exposição. Dessas três, duas são esculturas de Maria Martins e a outra, um quadro da artista suíça Sophie Taeuber-Arp. As três obras tangenciam a produção artística modernista feita por mulheres neste período na Europa, e que por muito tempo foi ignorada pela história da arte tradicional. Porém, esta aproximação não é estimulada pela curadoria, tornado-se possível apenas para quem já possui um conhecimento anterior sobre arte e artistas mulheres. Para mais, a presença destas obras continua a ser deficitária em relação a toda a exposição.

Outro ponto relevante na configuração das exposições em vigor no MAC USP é que todas as atuais mostras individuais são de artistas homens. Samson Flexor: traçados e abstrações, Fyodor Pavlov-Andreevich: monumentos temporários e Hugo França:

5 Para saber mais sobre o caso das mulheres no modernismo brasileiro, ver Simioni (20I7). 
um tronco para Exu - elas variam no espaço temporal em que seus artistas estão inseridos, mas todos são artistas contemporâneos, homens e brancos ${ }^{6}$.

Esse fato vai de encontro à produção crítica da história da arte chamada feminista, que aponta a ausência de artistas mulheres nos cânones da história da arte, assim como seus lugares específicos dentro das instituições da arte e as relações de poder na história da arte. Linda Nochlin, com o texto Why have there been no great women artists? (I97I), inaugura a problemática da ocultação das artistas mulheres na história da arte, apontando para a necessidade de se repensar as questões acerca desse tema. Outras autoras, como Susan Blas Brunel, no trabalho Trabajadoras del arte y economía de cuidados: una valoración desde la experiencia personal (2013), pensam no papel que as mulheres executam dentro das instituições de arte e como isso também está inserido numa perspectiva regida por uma hierarquia de gêneros. Tudo isso tem representação dentro do MAG USP, e é perpetuado com o apagamento da presença de mulheres nas exposições que o museu produz e cedia.

No entanto, esse é um fato no mínimo controverso, pois o MAG USP é uma instituição um tanto diferenciada de outras, principalmente no cenário latino-americano, já que é um dos poucos museus que sediaram exposições que tratam da questão da mulher na história da arte. Em I996, o MAG USP apresentou a exposição Mulheres artistas no acervo do MAC, com 95 obras de mulheres, como Tarsila do Amaral, Mira Schendel e Tomie Ohtake, e cuja montagem aponta uma intenção da instituição de resgatar obras esquecidas (TVARDOVSKAS, 20I5). Mais recentemente, Lisbeth Rebollo Gonçalves e Claudia Fazzolari foram as responsáveis por três exposições que contemplavam artistas latino-americanas, muitas delas que trabalham com a temática feminista, denominadas Mulheres artistas: olhares contemporâneos, de 2007, Mulheres artistas, relatos culturais, de 2008, e Corpos estranhos, de 2009 (TVARDOVSKAS, 20I5).

Outro ponto que diferencia o MAC USP das demais instituições é que a maior parte do corpo docente do museu, responsável pela Divisão de Pesquisa: Teoria e Crítica da Arte, de onde saem as curadorias das exposições, é com-

$6 \mathrm{Na}$ primeira versão deste trabalho, produzida em dezembro de 20I6, estavam em exposição as mostras Rafael França: entre mídias, Samson Flexor: traçados e abstrações, Júlio Plaza: indústria poética, Gustavo Von Ha: inventário; arte outra, Alex Flemming: retroperspectiva e Goeldi \ardim: a gravura e o compasso, o que quantitativamente corroborava ainda mais a argumentação. Porém, mesmo com a diminuição atual do número de exposições individuais, elas continuam a seguir o perfil aqui exposto. Complemento também que das três exposições citadas, a primeira permanecerá em cartaz até dezembro de 20I8, enquanto as outras foram finalizadas em agosto de 2017 (fonte: <http://www.mac.usp.br/mac/conteudo/exp/atuais/masterpager. asp> Acesso em: I8 set. 20I8). 
posta por mulheres. Atualmente, são vinculadas a esta divisão do MAC USP as professoras Helouise Costa, Cristina Freire, Ana Magalhães e o professor Edson Leite, sendo a primeira responsável pela chefia da divisão. Susana Blas Brunel (20I3) afirma que existem apenas $22 \%$ de mulheres dirigindo museus, em oposição à porcentagem daquelas que ocupam postos de conservação, chefia e coordenação de exposições temporárias, que é de 8I\% nos museus do mundo. Em consonância com esta crítica, a diretoria do MAC USP é ocupada por um homem, Carlos Roberto Ferreira Brandão, enquanto a função de vice-diretora é designada a uma mulher, Katia Canton (que também é a curadora da exposição A casa, que ficou em cartaz no museu até 9 de setembro de 20I8). Além disso, a Divisão Técnico-Científica do Acervo é chefiada por Paulo Roberto Amaral Barbosa, enquanto todos os outros cargos de restauro são ocupados por mulheres, salvo nos cargos técnicos. Apenas a Divisão Técnico-Científica de Educação e Arte, Projetos Especiais e Produção de Exposições e o Serviço de Biblioteca e Documentação são chefiadas por mulheres. A esse respeito, Susana Blas Brunel explica que:

Si un departamento tiene que elegir entre dos candidatos (hombre y mujer) de curriculum similar para ocupar la dirección y la subdirección/coordenación, es muy problabe que se elija al hombre para dirigir y a la mujer para coordenar, no tanto por los meritos del hombre, sino por su incapacidad o negativa para desempeñar el segundo puesto. Mientras la mujer podría servir por capacidades, entrega y talento para ambas funciones, el hombre 'o no sabe coordinar/organizar' o no está dispuesto a hacerlo (20I3, p. 43).

O que nos faz pensar na situação do MAC USP, onde a maioria (se não todas) das curadorias atuais são feitas por mulheres, porém são os homens que respondem pelos cargos de maior prestígio e hierarquia. A lógica permanece e, a despeito do espaço que essas mulheres curadoras poderiam articular em continuidade ao trabalho que pensa as questões de gênero no acervo do museu já desenvolvido nos anos I990 e primeira década dos anos 2000, essas profissionais continuam a reproduzir o apagamento da presença feminina dentro das obras "mais expressivas do riquíssimo acervo que o Museu abriga" (BRANDÃO, 20I6).

É possível afirmar isso ao observar a porcentagem de obras feitas por artistas homens e artistas mulheres em Visões da arte no acervo do MAC USP 19OO2000, mais especificamente em Visões da arte no acervo do MAC USP 1950-2000. Das 43 obras expostas, apenas I2 são feitas por artistas mulheres, correspondendo a uma porcentagem de $27,9 \%$ do total. Entre o total de obras, quatro são 
séries artísticas e duas delas são de autoria feminina. Das I2 obras de artistas mulheres, três são da artista Regina Silveira - e, ainda é importante ressaltar, as nove artistas que têm seus trabalhos expostos nessa exposição são brancas ${ }^{7}$.

A exposição está dividida em seis salas, projetadas pela curadoria ainda sob a ideia de balizas cronológicas que não são rígidas, mas orientam o público pelo percurso. O espaço expositivo possui ainda duas entradas, uma numa das laterais do espaço e outra na sala central da exposição; usarei como referência a entrada da lateral, pois ela possibilita um percurso linear e ainda orientado pelo sentido cronológico proposto pela curadoria. Desta forma, a primeira sala da exposição corresponde à seção denominada Figurações, cujo texto de apoio foi produzido por Helouise Costa (20I6) e fala da ruptura com a anterior abstração (penúltima seção do $7^{\circ}$ andar da exposição, Visões da arte no acervo do $M A C$ USP 1900-1950) que tomou conta do mundo da arte, no campo internacional e nacional. Nesta sala, existe apenas uma obra de autoria feminina: Inês, da artista suíça naturalizada brasileira Claudia Andujar, que a produziu no mesmo período referido por Helouise Costa nesta seção expositiva. Ela traz duas fotografias de um mesmo rosto feminino em uma expressão melancólica.

A segunda sala corresponde à seção Arte Política, cujo texto também é assinado por Helouise Costa (20I6). A ideia é o ano de I968 como marco de contestação política internacional que também influenciou a arte conceitual, em que os artistas questionam as relações de poder, o governo, a mídia e as instuições, fomentando a utilização de novas mídias como suporte artístico. Esta é a seção com maior presença de artistas mulheres, num total de cinco obras, incluindo duas séries, uma com três telas de Cybèle Varela e outra com I5 telas de Regina Silveira - esta última, inclusive, destaca-se no espaço expositivo, pois preenche praticamente toda a parede do corredor central da exposição e se apresenta como um ícone da ideia de arte e política que a seção quer evocar. A série de Cybèle Varela é talvez a mais fecunda para pensar o gênero entre as obras expostas: denominada De tudo aquilo que pode ser I, II e III, ela traz a mesma cena de uma rua com três figuras femininas fragmentadas, e em cada tela um "pedaço" das figuras está num lugar diferente, criando assim imagens como uma freira de saia curta ou sem a parte inferior do corpo; ela pode então ser compreendida como um jogo com as possibilidades de ser e existir dessas figuras femininas, e, ao ser contextualizada nesse período histórico em que

7 A questão racial nas instituições de arte merece um aprofundamento que não caberá nestas páginas. Por isso, deixo a referência de Barros (20I6), um texto que oferece um panorama interessante sobre o assunto. 
foi produzida e referenciada por Helouise Costa, localiza-se num período de marcante opressão sobre o modo como as mulheres deveriam ser, colocando em foco, portanto, uma singularidade da existência feminina. Vale lembrar, no entanto, que essa é apenas uma interpretação, que não pode ser confirmada, pois, como já foi citado, as artistas aqui presentes não possuem nenhum compromisso com uma problemática de gênero. Entretanto, nota-se com isso que a representação do gênero não é um tema tocado pela curadoria.

Além desta série, Regina Silveira tem exposta uma pequena coleção de quatro vídeos feitos por ela entre I977 e I978, ao lado da obra de vídeo da artista Analívia Cordeiro, na posição de destaque que a curadoria dá às obras em vídeo. É importante notar que estas são as únicas duas obras de videoarte, o que sugere uma representatividade interessante, já que videoarte é uma linguagem muito relevante dentro do campo artístico contemporâneo. Além dessas obras, também está presente o objeto Poço, de Amelia Toledo. É possível estabelecer relações entre as obras desta sala a partir dos pontos aqui expostos, mas esse é um exercício individual, não algo exposto ou estimulado pela curadoria.

A seção seguinte, a praça central do espaço expositivo, é dedicada ao MAC USP como projeto museológico, e assim retrata os projetos arquitetônicos de Paulo Mendes da Rocha para abrigar o Museu de Arte Contemporânea da USP. Aqui, apenas uma obra de autoria feminina está exposta, o quadro da artista húngara naturalizada brasileira Yolanda Mohalyi.

A sala seguinte corresponde ao texto Arte como ideia, de Carmem Aranha (20I6), e nela há uma obra que também traz uma figuração feminina, um rosto em sequência e um busto feminino nu de costas, que se projeta e ocupa quase toda a parede frontal no sentido que estou seguindo, mas dessa vez a autoria é do artista japonês Kozo Mio. Esta sala traz ainda um objeto de Mira Schendel, que talvez seja a artista contemporânea mais reconhecida entre os nomes escolhidos para compor a exposição, e uma fotografia de Regina Vater.

A penúltima e a última salas correspondem à seção que o texto Por uma arte global: a arte contemporânea na virada do século XXI, por Ana Magalhães (20I6), acompanha. A ideia é contrapor o retorno à pintura, chamado de neoexpressionismo, ao cenário global, que se transforma politicamente e vê a popularização da internet, e a associação disso à reformulação do conceito de autoria dentro da arte. A última sala é toda composta por serigrafias de Robert Rauschenberg, mas a penúltima sala traz pinturas de Carmela Gross e Regina Silveira.

Assim, pode-se observar que em todas as seções da exposição pelo menos uma obra de artistas mulheres está presente, o que é um déficit expressivo diante da presença de mulheres na produção artística contemporânea. Todas as artistas 
que têm obras expostas ou são brasileiras ou produziram em algum momento no Brasil, e todas elas, como é esperado, são mulheres brancas. Também é possível afirmar que nenhuma delas trabalha com temáticas de sexualidade em suas obras, o que aponta para outras ausências dentro da Visões da arte no acervo do MAC USP 19502000. Com este apontamento não quero dizer que todas as temáticas e representações devem estar presentes em todas as exposições de arte, mas apenas chamo atenção para o fato de uma exposição que se pretende panorâmica, que pretende expor as mais importantes obras de um acervo riquíssimo como é o do MAC USP, negligencia obras que retratem outras realidades que não as exaustivamente tratadas, construídas e reproduzidas pela academia de arte tradicional brasileira, como, por exemplo, a relação da arte conceitual e política, principalmente em países latino-americanos durante os regimes ditatoriais, as relações da arte com a tecnologia etc. Durante o período retratado pela exposição, diversos outros movimentos de arte existiram no Brasil e no mundo e têm obras que pertencem ao acervo do museu, mas continuam a ser ignorados pelo academicismo, e isso salta aos olhos na exposição de uma instituição acadêmica como o MAC USP.

\section{Conclusão}

A exposição Visões da arte no acervo do MAC USP 1900-2000 figura-se como mais uma das milhares de exposições acadêmicas que apagam a representatividade de artistas mulheres em todo o mundo. A segunda parte da exposição, intitulada Visões da arte no acervo do MAC USP 1950-2000, explicita ainda mais essa situação, pois privilegia obras contemporâneas de artistas homens em detrimento da obras de mulheres, e essas ainda em detrimento de obras de artistas mulheres que tenham uma relação com a temática do feminismo ou algo que não seja acadêmico, como a história das exposições montadas pelo próprio MAC USP comprova que a instituição possui ${ }^{8}$.

Este fato preocupa quando pensamos que o MAG USP, como museu universitário, deveria ser um espaço de maior renovação tanto das produções artísticas quanto dos discursos de teoria e crítica de arte, mas continua a reproduzir as ideias de um campo tradicionalista que foi erigido sob um ponto de vista masculino e heteronormativo. Isso também vai de encontro à ideia de irregularidade de percurso das grandes instituições museológicas desde o recrudescimento da crítica de arte feminista a partir dos anos I970,

8 Sobre as relações de gênero na seleção curatorial, ver mais em Silva e Silva (20I4). 
pois revela os altos e baixos quanto a esse tipo de abertura teórica dentro da hierarquia do museu. O mais alarmente, porém, é que na atual situação do museu as responsáveis pelo projeto que resultou na exposição aqui tratada são acadêmicas que, mesmo tendo contato com a teoria crítica feminista, continuam mantendo o mesmo padrão patriarcal na organização de exposições de obras de arte nos museus, isto é, continuam mantendo uma seleção curatorial na qual privilegiam obras e criações de autoria masculina, sobrepondo-as aos trabalhos significativos de muitas mulheres.

Se pensarmos que o apagamento da presença feminina nos grandes museus de arte contemporânea é resultado de toda uma articulação do circuito artístico mercadológico, advinda da construção sexista da disciplina história da arte e da sua criação de cânones, é apenas uma articulação entre todos os personagens desse mercado que possibilitaria uma igualdade entre gênero, raças e classes. Rui Pedro Fonseca (2013) afirma que só um equilíbrio entre exposição e consagração de artistas homens e mulheres, mediante a implementação de políticas focadas na igualdade de gênero, aumentará as possibilidades de desenvolver as carreiras artísticas das mulheres, o que aumentará o ensejo de consagração destas artistas, e nisto é indispensável a mobilização de agentes artísticos que tenham interesse em aumentar a visibilidade e garantir o devido valor as mulheres (FONSEGA, 20I3). Este, porém, não parece ser o caso dentro do atual MAC USP, que tanto não expõe quanto ignora a existência dessas relações sexualizadas no campo artístico.

Neste sentido, concordo com a autora Rocio de La Villa Ardura (2013), que afirma que um museu que preze por sua excelência educativa deve dispor de ferramentas pedagógicas simples que evidenciem as construções de gênero dentro da história da arte. Portanto, a única forma de amenizar esse tipo de apagamento deliberado é pelo serviço educativo do museu, que permitiria uma construção de significados que vá além do que o proposto pela curadoria. $\mathrm{O}$ serviço educativo do MAC USP, como é de se esperar, não tem essa pauta como prioridade, mas urgem novas tentativas de suprir essa necessidade urgente.

\section{Referências}

ARANHA, G. S. G. Arte como ideia. 20I6. Disponível em: 〈https://bit.ly/2vByGiR>. Acesso em: I4 dez. 2016.

AYERBE, J. Por que este texto nunca foi traduzido? Por que no Brasil os grandes artistas são mulheres? In: NOCHLIN, L. Por que não houve grandes mulheres artistas? São Paulo: Aurora, 20I6. p. 26-27. 
BARBOSA, A. M. Arte no Brasil: várias minorias. Gênero, Niterói, v. 3, n. 2 , p. I29-I36, 2003 .

BARROS, J. Artistas e instituições: é preciso colorir para enxergar. O Menelick $2^{O}$ ato, out. 20I6. Disponível em: 〈https://bit.ly/2AYFtHQ〉. Acesso em: 20 jul. 2017.

BLAS BRUNEL, S. Trabajadoras del arte y economía de cuidados: una valorizacón desde la experiencia personal. Investigaciones Feministas, Madrid, v. 4, p. 39$47,2013$.

BRANDÃO, G. A. F. Visões da Arte no Acervo do MAC USP 1900-200o. 20I6. Disponível em: 〈https://bit.ly/2nlWItR>. Acesso em: I4 dez. 2016.

COSTA, H. Arte política. 20I6a. Disponível em https://bit.ly/2nwrv6y>. Acesso em: I4 dez. 2016.

Figurações. 20I6b. Disponível em: 〈https://bit.ly/2Mkj645〉. 2016. Acesso em: I4 dez. 2016.

DE LA VILLA ARDURA, R. Crítica de arte desde la perspectiva de género. Investigaciones Feministas, Madrid, v. 4, p. IO-23, 2013.

FONSEGA, R. P. Carreira, arte feminista e mecenato: uma abordagem à dimensão econômica do circuito artístico principal sob uma perspectiva de gênero. Sociologia, v. 26, p. II3-I37, 2013.

MAGALHÃES, A. Por uma arte global: a arte contemporânea na virada do século XXI. 20I6. Disponível em: 〈https://bit.ly/2OqXyQU〉. Acesso em: I4 dez. 2016.

NOCHLIN, L. Why have there been no great women artists?. Women, Art and Power and Other Essays, New York, Westview Press, p.I47-I58, I988.

POLLOGK, G. Vision and difference: feminity, feminism, and histories of art. London: Routledge, I988.

SILVA, R. C.; SILVA, U. R. Memória e poder: mulheres artistas nas exposições museológicas no Brasil e em Portugal. Confluências Culturais, Joinville, v. 3, n. I, p. 57-68, 20I4.

SIMIONI, A. P. C. Anita Malfatti: do centro às margens... uma revisão necessária. Moderno Extra, São Paulo, v. 9, n. 6, p. II-24, 2017.

TVARDOVSKAS, L. S. Dramatização dos corpos: arte contemporânea e crítica feminista no Brasil e na Argentina. São Paulo: Intermeios, 2015.

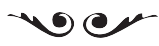

Bruna Fernanda Vieira Silva é graduanda em História pela Universidade de São Paulo.

bruna.fernandaO3@hotmail.com 